in vivo $35: 2957-2961(2021)$

doi:10.21873/invivo.12589

\title{
Unusual Presentation of a Post-procedural Breast Hematoma: A Case Report
}

\author{
GIANLUCA VANNI ${ }^{1}$, DOMIZIANA PEDINI ${ }^{1}$, MARCO MATERAZZO $^{1}$, ANDREA FARINACCIO $^{2}$, \\ TOMMASO PERRETTA ${ }^{3}$, CHIARA ADRIANA PISTOLESE ${ }^{3}$ and ORESTE CLAUDIO BUONOMO ${ }^{1}$ \\ ${ }^{1}$ Breast Unit, Department of Surgical Science, Policlinico Tor Vergata University, Rome, Italy; \\ ${ }^{2}$ Cardiac and Thoracic Anesthesia Unit, Tor Vergata University Hospital, Rome, Italy; \\ ${ }^{3}$ Department of Diagnostic Imaging and Interventional Radiology, \\ Molecular Imaging and Radiotherapy, Policlinico Tor Vergata University, Rome, Italy
}

\begin{abstract}
Background/Aim: Hematoma is the most frequent complication after Vacuum-Assisted Breast Biopsy (VABB) in $13 \%$ of cases. A direct communication channel with patients eases the diagnosis of $V A B B$ complications and ensures treatment at an early stage, as outpatients, in most cases. In 2020, due to the COVID-19 pandemic, we observed a reduction of self-reported postoperative complication leading to delay in the identification of harmful complications, therefore leading to need for more invasive treatment. Case Report: A 50-year-old patient was admitted to the Emergency Department for dry cough, fever, chest discomfort, dyspnea, and slight confusion four days after VABB. Due to the reported symptoms, the patient was sent to our COVID-19 Emergency Department. The COVID-19 swab was negative. Ultrasound revealed a large hematoma at the biopsy site, with active bleeding. Open evacuation with accurate hemostasis was planned with rapid and complete resolution of the clinical symptoms. After surgery, the patient reported that she intentionally avoided admittance in the hospital due to the risk of COVID-19 infection. The patient was discharged in the first postoperative day and maintained in quarantine for 14 days. Conclusion: In the COVID-19 era due to the risk of hospital cross-infections, reduction of patientdoctor communication could lead to misdiagnosis, delay in recognition of procedural complications thus leading to requirement for invasive treatment, hospitalization, while also further multiplying the risk of COVID-19 infection.
\end{abstract}

This article is freely accessible online.

Correspondence to: Marco Materazzo, Breast Unit, Department of Surgical Science, PTV: Policlinico Tor Vergata University, Viale Oxford 81, 00133 Rome, Italy. Tel: +39 3395685883, e-mail: marco.materazzzo@ptvonline.it

Key Words: Breast biopsy, post-procedural hematoma, vacuumassisted biopsy, Covid-19, case report.
Breast Cancer $(\mathrm{BC})$ represents the most common neoplasia worldwide, affecting more than 2.3 million women yearly (1). Patient tailored treatment encompasses a combination of surgery, medical, and radiation oncology treatment (2-4). Keeping in mind the complexity of BC treatment options, careful diagnostic assessment is imperative to choose for the best treatment strategy for each patient to reduce locoregional (5-7) and distant relapse $(8,9)$.

Diagnostic assessment requires a complete clinical evaluation, so called triple assessment, which includes physical examination, imaging (mammography and/or ultrasound), and needle biopsy [fine needle aspiration cytology (FNAC), core needle biopsy (CNB), or vacuumassisted breast biopsy (VABB)] (10).

Among different needle biopsy procedures, VABB gained popularity thanks to the achievement of bigger sampling within a single insertion and lower rate of false-negative results $(11,12)$. Moreover, VABB procedure allows the complete removal of small benign lesions, especially when smaller than $10 \mathrm{~mm}$ (13), representing a safe technique with a low rate of major complications (2.1\%) even when performed with larger needles (8 or 11 Gauge) $(14,15)$. Most common minor complication are represented by hematoma, with an incidence of $13 \%$ (16).

In order to identify any early VABB complication, most of the BC Centre facilities developed a telephonic direct communication system between health care providers and patients (17). In our experience, the direct communication system provided diagnosis at presentation or at an early stage, allowing for early conservative treatment, in the majority of cases. In 2020, due to the COVID-19 pandemic, we observed a reduction of self-reported VABB postoperative complications. This reduction could lead to a delay in the identification of harmful complication and more invasive treatment. Hence, we report a case of a patient with postprocedure complication which required surgical exploration due to the deliberately delay of patient hospital admission. 


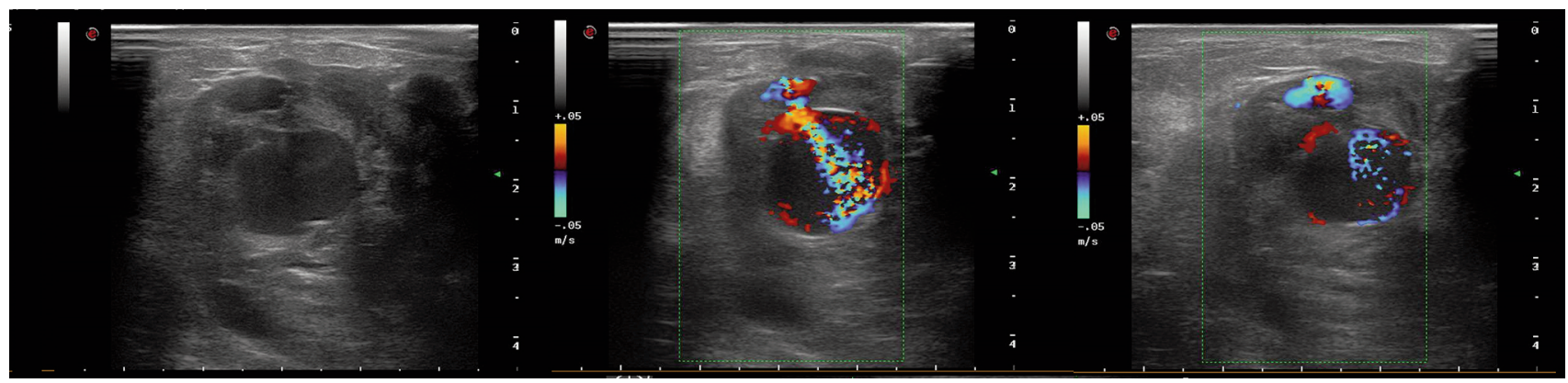

Figure 1. Breast ultrasound. From left to right morphologic ultrasonographic assessment and color-doppler with active bleeding.

\section{Case Report}

In late December 2020, a 50-year-old female patient was admitted to the Emergency Department at our Institution for a worsening dry cough, fever $\left(37.5^{\circ} \mathrm{C}\right)$, chest discomfort and feeling of pressure associated with shortness of breath, fatigue and slight confusion. Symptom onset dated back to three days earlier. The patient was initially admitted to our COVID-19 Emergency Department.

Oxygen saturation was stable at $99 \%$ with $\mathrm{PaO}_{2}=85$ $\mathrm{mmHg}$ and $\mathrm{PCO}_{2}=38 \mathrm{mmHg}$. Electrolytes were within the normal limits. Hemoglobin $(\mathrm{Hb})$ levels at admission were $11.7 \mathrm{~g} / \mathrm{dl}$ with Hematocrit $(\mathrm{Ht})$ of $33.5 \%$. Phlogosis indices were found to be all within normal limits, with C-reactive protein of $5.3 \mathrm{mg} / \mathrm{l}(\mathrm{N}: 0-5.0 \mathrm{mg} / \mathrm{l})$ and conserved leukocyte count. Both diagnostic and confirmatory COVID-19 swabs tested negative.

Chest physical examination did not reveal abnormalities on auscultation or percussion of the thorax. A marked asymmetry of the left breast was described upon inspection. The swelling appeared as non-erythematous and the patient did not complain of localized tenderness other than the aforementioned discomfort. The left breast was tender on palpation. The patient had undergone a VABB of the left breast four days earlier as a monitoring measure of a microcalcification cluster localized at the external-superior quadrant. VABB was performed by Mammotome ${ }^{\circledR}$ (Devicor Medical Products, Inc. Cincinnati, OH, USA) with an 8Gauge needle, stereotaxic technique-guided. Despite not experiencing any immediate complication at the time of the procedure, the patient reported a progressive swelling since post-procedure day 1 . The patient was following a prophylactic antibiotic treatment (Augmentin $875 \mathrm{mg} / 125$ $\mathrm{mg}$ twice a day, for 5 days) as per protocol and the compressive bandage was congruously in place. The patient reported she intentionally avoided further contacts with the hospital due to the risk of Sars-Cov-2 infection, and only the onset of fever has led to the Emergency Department self-referral.
Emergency ultrasound showed a $2.5 \times 1.6 \mathrm{~cm}$ hematoma and a pulsatile active bleeding of the core biopsy site detected by color-doppler assessment (Figure 1). This finding was associated with a loss of 1 unit of $\mathrm{Hb}$ (stable $\mathrm{Ht}$ : $33 \%$ ) and a progressive decline of the general clinical condition. The volume of hematoma as well as the persistence and intensity of the bleeding required an accurate hemostasis of the site, not feasible with an emergency drainage.

Open hematoma evacuation and Argon Beam Coagulator hemostasis were performed. Immediately following the hematoma evacuation, rapid and complete resolution of the clinical symptoms was observed. Postoperative course was uneventful and patients was discharged during the first postoperative day.

During hospital admission, the patient was maintained isolated and surgical procedure was performed in the COVID-19 surgical room because of the prior admission in the COVID-19 Emergency Department. After discharge, due to the aforementioned reason, the patient maintained in quarantine for 14 days and COVID-19 swab test was performed at the end of quarantine, which was negative (18).

\section{Discussion}

The VABB procedure is a safe option to complete the triple assessment of newly-diagnosed breast lumps $(14,15)$. Major complications encompass bleeding at the biopsy site which does not cease even under manual or bandage compression following the procedure. Dahabreh et al. reported the results of eight studies on ultrasound guided vacuum assisted biopsies identifying an hematoma incidence of $13 \%$ and a bleeding rate of $2.5 \%$ (16).

Schaefer et al. reported significantly more bleedings and post-interventional hematomas with 8 -gauge-Mammotome ${ }^{\circledR}{ }_{-}$ system vs. 11-gauge-Mammotome ${ }^{\circledR}$-system (41.9\% vs. $8.4 \%$, $p<0.001 ; 35.5 \%$ vs. $16.7 \%, p=0.029)$ while no significant differences were reported regarding the ATECR-systems 9gauge vs. 12-gauge ( $26.9 \%$ vs. $29.7 \%, p=0.799 ; 42.3 \%$ vs. $43.2 \%, p=0.596$ ) (19). Conversely, Hahn et al. did not manage 
to define a significant difference between the use of 8 or 11 Gauge needle in diagnostic reliability, nor in hematoma incidence and volume or resolution $(p=0.2)(20)$. Zagouri et al. reported that clinically significant and subsequently organized hematomas were significantly more frequent in the extended protocol than in the standard protocol $(7.5 \%$ vs. $3.5 \%, p=0.038)$ (21), also concluding that the likelihood of hematoma increases proportionally to the amount of intraoperative blood loss, with a plateau being reached at approximately $80 \mathrm{cc}(22,23)$.

In 2008, Zografos et al. indicated the insertion of a Fogarty catheter as an option to limit or prevent the development of hematomas following $\operatorname{VAB}(24,25)$. In 2015, Shao-Mei et al. also reported the effect of using a fully inflated Foley catheter after VAB, right at the site of the procedure $v s$. manual compression, with promising results $(p=0.002)$ in hematoma incidence reduction (26).

What made the case of our patient unique was its unusual clinical presentation with symptoms suggestive of a phlogistic process, however, physical examination and laboratory tests failed to show any relevance of the diagnosis, even before the molecular swab was confirmed as negative $(27,28)$.

We believe such atypical presentation should be attributed to the inflammatory micro-environment developing at the site of the VAB procedure. In 2009, Zografos et al. described the analysis of serial venous samples collected from 36 patients prior to, at the end and 1 hour following a stereotaxic VAB in which Interleukin (IL)-1 $\alpha$, IL-1 $\beta$ and IL-6 levels were measured to assess a potential link to the likelihood of developing a hematoma and its evolution (organization or progression). IL- $1 \alpha$ and IL-1 $\beta$ levels did not exhibit significant changes while IL-6 serum levels trend of above $5.5 \mathrm{pg} / \mathrm{ml} 1$ hour following VAB or of $4 \mathrm{pg} / \mathrm{ml}$ increase above the baseline was found to be alarming for hematoma formation $(29,30)$. Further studies are required to determine a threshold or any other serological marker that could delineate the distinction between hematomas that require further interventions and those that do not (29, 31-33).

Most of all, our case is very representative of the impact of the COVID-19 pandemic on our patients. The fear of contracting the infection led to a lack of communication, a crucial aspect within the system of our Breast Unit (28). All our patients have a direct channel of communication with health care providers, meaning that the most frequent complications such as bleeding and hematomas can be solved at presentation at the outpatient clinic with no need for invasive procedures.

In this case, the patient deliberately avoided reporting her condition due to fear of contracting COVID-19 at our outpatient clinic. Reduction of surgical emergency access with an higher rate of hospitalization, it is a well-known effect of COVID-19 pandemic and this clinical case confirmed previous evidence in larger series $(34,35)$. In fact, patient self-referred to Emergency Department only when her clinical condition deteriorated. Due to the symptoms reported, patient after triage was sent to our COVID-19 Emergency Department, multiplying her chances of contracting the infection.

After diagnosis, patient required an open procedure with inpatient admission due to the more advanced phase of hematoma. The delayed presentation led to the need for an invasive procedure to treat a common complication that would have been otherwise treated conservatively. Moreover, due to the first admission in the COVID-19 section, the patient required 14 days quarantine and further COVID-19 swab test at home, impacting on patient's return to daily activities and work. Additionally, due to the cross-infection risk, all health care workers wore personal protective equipment (PPE) to reduce cross infection in oncological frail patients $(36,37)$.

\section{Conflicts of Interest}

The Authors declare no conflicts of interest regarding this study.

\section{Authors' Contributions}

Gianluca Vanni, Oreste Claudio Buonomo performed the surgical procedure; Domiziana Pedini, Marco Materazzo reviewed literature data, Tommaso Perretta, Chiara Adriana Pistolese preoperative investigation the patient, Domiziana Pedini, Andrea Farinaccio prepared the draft of the manuscript, Oreste Claudio Buonomo was advisor of the surgical procedures, Marco Materazzo, Buonomo Oreste Claudio, Gianluca Vanni reviewed the final version of the manuscript. All the Authors read and approved the final version of the manuscript.

\section{Acknowledgements}

The work was financially supported by Italian Ministry of Health.

\section{References}

1 Sung H, Ferlay J, Siegel RL, Laversanne M, Soerjomataram I, Jemal A and Bray F: Global Cancer Statistics 2020: GLOBOCAN estimates of incidence and mortality worldwide for 36 cancers in 185 countries. CA Cancer J Clin 71(3): 209249, 2021. PMID: 33538338. DOI: 10.3322/caac.21660

2 Waks AG and Winer EP: Breast cancer treatment: A review. JAMA 321(3): 288-300, 2019. PMID: 30667505. DOI: 10.1001/ jama.2018.19323

3 Roselli M, Guadagni F, Buonomo O, Belardi A, Ferroni P, Diodati A, Anselmi D, Cipriani C, Casciani CU, Greiner J and Schlom J: Tumor markers as targets for selective diagnostic and therapeutic procedures. Anticancer Res 16(4B): 2187-2192, 1996. PMID: 8694541.

4 Buonomo O, Cabassi A, Guadagni F, Piazza A, Felici A, Piccirillo R, Atzei GP, Cipriani C, Schiaroli S, Mariotti S, Guazzaroni MN, Cossu E, Simonetti G, Pernazza E, Casciani $\mathrm{CU}$ and Roselli M: Radioguided-surgery of early breast lesions. Anticancer Res 21(3C): 2091-2097, 2001. PMID: 11501831. 
5 Buonomo OC, Grasso A, Pistolese CA, Anemona L, Portarena I, Meucci R, Morando L, Deiana C, Materazzo M and Vanni G: Evaluation of concordance between histopathological, radiological and biomolecular variables in breast cancer neoadjuvant treatment. Anticancer Res 40(1): 281-286, 2020. PMID: 31892577. DOI: 10.21873/anticanres.13950

6 Orsaria P, Caredda E, Genova F, Materazzo M, Capuano I, Vanni G, Granai AV, DE Majo A, Portarena I, Sileri P, Petrella G, Palombi L and Buonomo OC: Additional nodal disease prediction in breast cancer with sentinel lymph node metastasis based on clinicopathological features. Anticancer Res 38(4): 2109-2117, 2018. PMID: 29599329. DOI: 10.21873/anticanres. 12451

7 Ielpo B, Pernaute AS, Elia S, Buonomo OC, Valladares LD, Aguirre EP, Petrella G and Garcia AT: Impact of number and site of lymph node invasion on survival of adenocarcinoma of esophagogastric junction. Interact Cardiovasc Thorac Surg 10(5): 704-708, 2010. PMID: 20154347. DOI: 10.1510/icvts.2009. 222778

8 Ielpo B, Mazzetti C, Venditti D, Buonomo O and Petrella G: A case of metachronous splenic metastasis from renal cell carcinoma after 14 years. Int J Surg 8(5): 353-355, 2010. PMID: 20438874. DOI: 10.1016/j.ijsu.2010.04.006

9 Buonomo OC, Caredda E, Portarena I, Vanni G, Orlandi A, Bagni C, Petrella G, Palombi L and Orsaria P: New insights into the metastatic behavior after breast cancer surgery, according to well-established clinicopathological variables and molecular subtypes. PLoS One 12(9): e0184680, 2017. PMID: 28922402. DOI: 10.1371/journal.pone.0184680

10 Karim MO, Khan KA, Khan AJ, Javed A, Fazid S and Aslam MI: Triple assessment of breast lump: Should we perform core biopsy for every patient? Cureus 12(3): e7479, 2020. PMID: 32351857. DOI: 10.7759/cureus.7479

11 Wang T and Zhu L: Mammotome-assisted removal with minimal incision of large juvenile fibroadenoma of breast: A case report. Medicine (Baltimore) 99(10): e19442, 2020. PMID: 32150097. DOI: $10.1097 / \mathrm{MD} .0000000000019442$

12 Orsaria P, Grasso A, Carino R, Caredda E, Sammarra M, Altomare C, Rabitti C, Gullotta G, Perrone G, Pantano F, Buonomo $\mathrm{OC}$ and Altomare $\mathrm{V}$ : Heterogeneous risk profiles among B3 breast lesions of uncertain malignant potential. Tumori 106(2): 115-125, 2020. PMID: 31451072. DOI: 10.1177/ 0300891619868301

13 Bick U, Trimboli RM, Athanasiou A, Balleyguier C, Baltzer PAT, Bernathova M, Borbély K, Brkljacic B, Carbonaro LA, Clauser P, Cassano E, Colin C, Esen G, Evans A, Fallenberg EM, Fuchsjaeger MH, Gilbert FJ, Helbich TH, HeywangKöbrunner SH, Herranz M, Kinkel K, Kilburn-Toppin F, Kuhl CK, Lesaru M, Lobbes MBI, Mann RM, Martincich L, Panizza P, Pediconi F, Pijnappel RM, Pinker K, Schiaffino S, Sella T, Thomassin-Naggara I, Tardivon A, Ongeval CV, Wallis MG, Zackrisson S, Forrai G, Herrero JC, Sardanelli F and European Society of Breast Imaging (EUSOBI), with language review by Europa Donna-The European Breast Cancer Coalition: Imageguided breast biopsy and localisation: recommendations for information to women and referring physicians by the European Society of Breast Imaging. Insights Imaging 11(1): 12, 2020. PMID: 32025985. DOI: 10.1186/s13244-019-0803-x

14 Eller A, Janka R, Lux M, Saake M, Schulz-Wendtland R, Uder $M$ and Wenkel E: Stereotactic vacuum-assisted breast biopsy
(VABB) - a patients' survey. Anticancer Res 34(7): 3831-3837, 2014. PMID: 24982410.

15 Liberman L, Kaplan JB, Morris EA, Abramson AF, Menell JH and Dershaw DD: To excise or to sample the mammographic target: what is the goal of stereotactic 11-gauge vacuum-assisted breast biopsy? AJR Am J Roentgenol 179(3): 679-683, 2002. PMID: 12185043. DOI: 10.2214/ajr.179.3.1790679

16 Dahabreh IJ, Wieland LS, Adam GP, Halladay C, Lau J TT: Core needle and open surgical biopsy for diagnosis of breast lesions: An update to the 2009 report. Agency for Healthcare Research and Quality (US), 2014. Available at: https://www.ncbi.nlm. nih.gov/books/NBK246878 [Last accessed on June 4, 2021]

17 Ream E, Hughes AE, Cox A, Skarparis K, Richardson A, Pedersen VH, Wiseman T, Forbes A and Bryant A: Telephone interventions for symptom management in adults with cancer. Cochrane Database Syst Rev 6: CD007568, 2020. PMID: 32483832. DOI: 10.1002/14651858.CD007568.pub2

18 Ministero della Salute: Ricerca e gestione dei contatti di casi COVID-19 (Contact tracing) ed App Immuni, 2020. Available at: https://www.trovanorme.salute.gov.it/norme/renderNormsan Pdf ?anno=2020\&codLeg $=74178 \&$ parte $=1$ \&serie=null [Last accessed on June 4, 2021]

19 Schaefer FK, Order BM, Eckmann-Scholz C, Strauss A, Hilpert F, Kroj K, Biernath-Wüpping J, Heller M, Jonat W and Schaefer PJ: Interventional bleeding, hematoma and scar-formation after vacuumbiopsy under stereotactic guidance: Mammotome $\left({ }^{\circledR}\right)$-system $11 \mathrm{~g} / 8$ g vs. ATEC $\left({ }^{\circledR}\right)$-system 12 g/9 g. Eur J Radiol 81(5): e739-e745, 2012. PMID: 22381441. DOI: 10.1016/j.ejrad.2012.01.033

20 Hahn M, Okamgba S, Scheler P, Freidel K, Hoffmann G, Kraemer B, Wallwiener D and Krainick-Strobel U: Vacuumassisted breast biopsy: a comparison of 11-gauge and 8-gauge needles in benign breast disease. World J Surg Oncol 6: 51, 2008. PMID: 18489771. DOI: 10.1186/1477-7819-6-51

21 Zagouri F, Gounaris A, Liakou P, Chrysikos D, Flessas I, Bletsa G, Giannakopoulou G, Michalopoulos NV, Safioleas P, Zografos GC and Sergentanis TN: Vacuum-assisted breast biopsy: more cores, more hematomas? In Vivo 25(4): 703-705, 2011. PMID: 21709018.

22 Zagouri F, Sergentanis TN, Domeyer P, Chrysikos D, Giannakopoulou G, Michalopoulos NV, Safioleas P, Flessas I, Panopoulou E, Bletsa G and Zografos GC: Volume of blood suctioned during vacuum-assisted breast biopsy predicts later hematoma formation. BMC Res Notes 3: 70, 2010. PMID: 20226029. DOI: $10.1186 / 1756-0500-3-70$

23 Buonomo O, Granai AV, Felici A, Piccirillo R, De Liguori Carino N, Guadagni F, Polzoni M, Mariotti S, Cipriani C, Simonetti G, Cossu E, Schiaroli S, Altomare V, Cabassi A, Pernazza E, Casciani CU and Roselli M: Day-surgical management of ductal carcinoma in situ (DCIS) of the breast using wide local excision with sentinel node biopsy. Tumori 88(3): S48-S49, 2002. PMID: 12365390.

24 Zografos GC, Zagouri F, Sergentanis TN, Koulocheri D, Michalopoulos NV, Tsigris C, Bramis J and Gomatos IP: Use of fogarty catheter to limit hemorrhage and hematoma after vacuum-assisted breast biopsy. Acta Radiol 49(7): 752-754, 2008. PMID: 19143060.

25 Orsaria P, Chiaravalloti A, Fiorentini A, Pistolese C, Vanni G, Granai AV, Varvaras D, Danieli R, Schillaci O, Petrella G and Buonomo OC: PET probe-guided surgery in patients with breast cancer: Proposal for a methodological approach. In Vivo 31(1): 101-110, 2017. PMID: 28064227. DOI: 10.21873/invivo.11031 
$26 \mathrm{Fu}$ SM, Wang XM, Yin CY and Song H: Effectiveness of hemostasis with Foley catheter after vacuum-assisted breast biopsy. J Thorac Dis 7(7): 1213-1220, 2015. PMID: 26380737. DOI: $10.3978 / \mathrm{j}$.issn.2072-1439.2015.05.17

27 Vanni G, Materazzo M, Pellicciaro M, Ingallinella S, Rho M, Santori F, Cotesta M, Caspi J, Makarova A, Pistolese CA and Buonomo OC: Breast cancer and COVID-19: The effect of fear on patients' decision-making process. In Vivo 34(3 Suppl): 16511659, 2020. PMID: 32503825. DOI: 10.21873/invivo.11957

28 Oldani C, Vanni G and Buonomo OC: COVID-19 unintended effects on breast cancer in Italy after the great lockdown. Front Public Health 8: 601748, 2020. PMID: 33425839. DOI: 10.3389/ fpubh.2020.601748

29 Zografos GC, Zagouri F, Sergentanis TN, Koulocheri D, Flessas I, Provatopoulou X, Kalogera E, Michalopoulos NV, Bramis J and Gounaris A: Hematoma after vacuum-assisted breast biopsy: are interleukins predictors? Onkologie 32(7): 395-397, 2009 PMID: 19556816. DOI: 10.1159/000219366

30 Vanni G, Materazzo M, Perretta T, Meucci R, Anemona L, Buonomo C, Dauri $\mathrm{M}$, Granai $\mathrm{AV}$, Rho $\mathrm{M}$, Ingallinella $\mathrm{S}$, Tacconi F, Ambrogi V, Chiaravalloti A, Schillaci O, Petrella G and Buonomo OC: Impact of awake breast cancer surgery on postoperative lymphocyte responses. In Vivo 33(6): 1879-1884, 2019. PMID: 31662515. DOI: 10.21873/invivo.11681

31 Vanni G, Tacconi F, Sellitri F, Ambrogi V, Mineo TC and Pompeo E: Impact of awake videothoracoscopic surgery on postoperative lymphocyte responses. Ann Thorac Surg 90(3): 973-978, 2010. PMID: 20732526. DOI: 10.1016/j.athoracsur. 2010.04.070

32 Ferroni P, Roselli M, Spila A, D’Alessandro R, Portarena I, Mariotti S, Palmirotta R, Buonomo O, Petrella G and Guadagni F: Serum sE-selectin levels and carcinoembryonic antigen mRNA-expressing cells in peripheral blood as prognostic factors in colorectal cancer patients. Cancer 116(12): 2913-2921, 2010. PMID: 20336782. DOI: $10.1002 /$ cncr.25094

33 Piazza A, Adorno D, Poggi E, Borrelli L, Buonomo O, Pisani F, Valeri M, Torlone N, Camplone C, Monaco PI, Fraboni D and Casciani CU: Flow cytometry crossmatch: a sensitive technique for assessment of acute rejection in renal transplantation. Transplant Proc 30(5): 1769-1771, 1998. PMID: 9723274. DOI: 10.1016/s0041-1345(98)00423-0
34 Anteby R, Zager Y, Barash Y, Nadler R, Cordoba M, Klang E, Klein Y, Ram E, Gutman M and Horesh N: The impact of the Coronavirus disease 2019 outbreak on the attendance of patients with surgical complaints at a tertiary hospital emergency department. J Laparoendosc Adv Surg Tech A 30(9): 1001-1007, 2020. PMID: 32589496. DOI: 10.1089/lap.2020.0465

35 Vanni G, Legramante JM, Pellicciaro M, DE Carolis G, Cotesta M, Materazzo M, Buonomo C, Farinaccio A, Santori F, Saraceno F, Ielpo B, Aiello F, Paganelli C, Grande M, DE Andreis G, Chiocchi M, Palombi L and Buonomo OC: Effect of lockdown in surgical emergency accesses: Experience of a COVID-19 hospital. In Vivo 34(5): 3033-3038, 2020. PMID: 32871849. DOI: 10.21873 /invivo.12137

36 Vanni G, Materazzo M, Santori F, Pellicciaro M, Costesta M, Orsaria P, Cattadori F, Pistolese CA, Perretta T, Chiocchi M, Meucci R, Lamacchia F, Assogna M, Caspi J, Granai AV, DE Majo A, Chiaravalloti A, D'Angelillo MR, Barbarino R, Ingallinella S, Morando L, Dalli S, Portarena I, Altomare V, Tazzioli $G$ and Buonomo OC: The effect of Coronavirus (COVID-19) on breast cancer teamwork: A multicentric survey. In Vivo 34(3 Suppl): 1685-1694, 2020. PMID: 32503830. DOI: 10.21873/invivo.11962

37 Vanni G, Materazzo M, Dauri M, Farinaccio A, Buonomo C, Portarena I, Pellicciaro M, Legramante JM, Rizza S, Chiaramonte C, Bellia A, Grande M, Potenza S, Sbordone FP, Perrone MA, Grimaldi F, Chiocchi $\mathrm{M}$ and Buonomo OC: Lymphocytes, Interleukin 6 and D-dimer cannot predict clinical outcome in Coronavirus cancer patients: LyNC1.20 study. Anticancer Res 41(1): 307-316, 2021. PMID: 33419825. DOI: 10.21873/anticanres.14777
Received May 8, 2021

Revised May 31, 2021

Accepted June 4, 2021 